\title{
La cultura visual y la publicidad como herramientas para enseñar las figuras retóricas en el aula de español para extranjeros
}

\begin{abstract}
Resumen
Actualmente, el mundo se encuentra repleto de imágenes. El ser humano está dotado de una cultura y alfabetización visual vinculadas que facilitan el entendimiento de todo aquello que le rodea. En este artículo se presenta una experiencia educativa en la que se ha aprovechado dicha cultura visual para llevar al aula de español para extranjeros ocho figuras retóricas. Se parte de la hipótesis de que la alfabetización visual genera una serie de conocimientos que se pueden explotar en la práctica pedagógica, esencialmente al facilitar su comprensión y, por ende, colaborar en el proceso de enseñanza-aprendizaje del alumnado. Para ello, se ha llevado a cabo una investigación cuasi-experimental, por medio de una metodología activa y participativa basada en la observación y en la deducción de procedimientos retóricos a partir de imágenes publicitarias. Para comprobar la efectividad de la propuesta pedagógica se han sometido a análisis dos grupos: uno de control, en el que se aplicaba la enseñanza tradicional; y otro experimental, en el que se introducía un taller pedagógico de carácter horizontal. A través de esta práctica pedagógica se ha logrado que el grupo de discentes de español del grupo experimental, correspondiente a un nivel B2, reconociesen de forma visual ocho figuras retóricas bastante recurrentes en publicidad y mejorasen el dominio de dicho procedimiento retórico. La cultura visual ha permitido Ilevar al aula un contenido pedagógico difícil de comprender. Asimismo, el alumno ha sido protagonista y guía de su propio aprendizaje a través de la transformación de la estrategia pedagógica, en la que se relacionan conocimiento e interacciones comunicativas.
\end{abstract}

\author{
Laura María Aliaga Aguza \\ Doctora en Filología Hispánica. \\ Universidad Internacional Isabel I, \\ Burgos, España. \\ Correo electrónico: \\ lauramaria.aliaga@ui1.es \\ ๑ orcid.org/0000-0002-7301-5188 \\ Google Scholar
}

Recibido: abril 13 de 2021 Aprobado: junio 24 de 2021

Palabras clave:

alfabetización visual, cultura visual, didáctica de la lengua, pedagogía, publicidad. 


\section{Visual culture and advertising as tools to teach rhetorical figures in the Spanish as a foreign language classroom}

\begin{abstract}
Today the world is full of images. The human being is endowed with a culture and related visual literacy that facilitate the understanding of everything that surrounds him. The article presents an educational experience in which this visual culture has been used to introduce eight rhetorical figures to the Spanish as a foreign language classroom. It is based on the hypothesis that visual literacy generates a series of knowledge that can be used in pedagogical practice, essentially by facilitating its understanding and, therefore, collaborating in the teaching-learning process of students. To do so, quasi-experimental research has been carried out through an active and participatory methodology based on observation and the deduction of rhetorical proceedings from advertising images. To verify the effectiveness of the pedagogical proposal, two groups have been submitted to analysis: a control group, where traditional teaching was applied and an experimental group in which a horizontal pedagogical workshop was introduced. Through this pedagogical practice, it has been possible for the group of Spanish learners of the experimental group, corresponding to a B2 level, to visually recognize eight rhetorical figures very common in advertising and improve their mastery of said rhetorical procedure. Visual culture has made it possible to bring pedagogical content difficult to understand into the classroom. Likewise, students have been the protagonists and guides of their own learning through the transformation of the pedagogical strategy in which knowledge and communicative interactions are related.
\end{abstract}

Key words:

visual literacy, visual culture, language didactics, pedagogy, advertising. 


\section{Introducción}

En la actualidad, el ser humano está rodeado de imágenes que viajan por distintos medios, debido, esencialmente, al auge que ha experimentado la tecnología y la comunicación en las últimas décadas (Bang et al., 2021). No obstante, cabe matizar que esta proliferación de la imagen se debe, en gran medida, a la fácil difusión de las mismas, puesto que el ser humano ha convivido con la imagen desde tiempos remotos, ya que, como apunta Moles (1975), "sería legítimo plantearse la cuestión de la densidad de imágenes por metro cuadrado o por metro cúbico, tanto en el espacio global de la ciudad como en el espacio personal y centrípeto de la organización del mundo" (p. 65). Lo que ha cambiado desde entonces ha sido la hipervisualidad y la multiexpresividad que explora, descubre y analiza diferentes categorías visuales que permiten nuevas formas de transmitir conocimiento e información sociocultural (Toro, 2019). Por todo ello, el ser humano adquiere cultura visual de forma progresiva, y la alfabetización de la misma se suele considerar como un código de comunicación en un medio social concreto y delimitado en el tiempo, que le permite extraer conocimiento en el contexto en el que se inserta (Dondis, 1992). Asimismo, dicha alfabetización visual se encuentra en los medios de comunicación; en ellos se hace explícito el poder que tiene la imagen, puesto que llega al público de una forma más efectiva de lo que el texto escrito lo hace (Andueza, 2016). Desde este punto de vista, "el reinado de la imagen se ha vuelto omnipresente no solo como vehículo de comunicación, sino, sobre todo, de creación de sentido" (Piscitelli, 2005, p. 13), puesto que la imagen se constituye por la codificación de diversos signos en los que se puede inferir una lectura múltiple que "no se agota en lo que muestra la imagen, en lo puramente denotado" (Cao, 1998, p. 45), sino que posee un lenguaje figurativo muy rico, una alfabetización visual, en definitiva, que se puede aprovechar en el aula para desarrollar principios de educación y de intervención controlados desde una mirada pedagógica (Aliaga, 2020). 
La publicidad se nutre de esta cultura visual para llegar a su destinatario. Un método productivo en la persuasión hacia el consumidor es el uso de las figuras retóricas visuales, pues con ellas se consigue aunar una serie de referentes por medio de una sola imagen; en otras palabras, se entiende la retórica como "el repertorio de las diferentes maneras con las que se puede ser persuasivo al intentar transmitir una imagen y con ella una idea o un conjunto de ellas" (Cao, 1998, p. 61). Este método de lectura y de creación no es nuevo en la publicidad, autores como Barthes (1990) ya señalaban el uso de las figuras clásicas en los anuncios publicitarios para fomentar la creatividad de las ideas. La publicidad se nutre de la retórica visual como "herramienta de organización que se utiliza para interconectar los distintos significados de los componentes del producto visual" (Acaso, 2009, p. 86). En el lenguaje visual transmitido por la imagen "se produce un pensamiento visual y los caracteres que lo constituyen no son solo fonemas, sino un amplio y complejo espectro de elementos gráfico-plásticos e icónicos que conviven con los elementos denominados tradicionalmente como lingüísticos" (Andueza, 2016, p. 66).

Esta idiosincrasia de la alfabetización visual es la que se puede explotar en el aula, en general, y en la de español para extranjeros, en particular, en base a diseñar una intervención educativa en la que el discente aprende y piensa en una cultura visual con unos mecanismos retóricos que, desde una metodología tradicional en el proceso de enseñanza-aprendizaje, supone un procedimiento más tedioso, a la par que menos eficiente (Arriaga et al., 2018). Si bien es cierto que, para que la educación de la cultura visual sea eficaz, se deben considerar las tres fases del proceso de enseñanza-aprendizaje que establece Villafañe (2006): (a) la recepción de la información, en la que se desarrolla la sensación visual; (b) el almacenaje de la información, lo que se conoce como memoria visual; y (c) el procesamiento de la información, de naturaleza sensorial, que es el pensamiento visual. 
El objetivo de esta experiencia pedagógica fue demostrar cómo a partir de la alfabetización visual se pueden enseñar figuras retóricas en un nivel B2 del aula de español para extranjeros, un recurso que desde la metodología tradicional resulta de difícil comprensión (Carratalá, 2013). De este objetivo nuclear se desprende otro: transformar información en conocimiento y conocimiento en educación, creando ámbitos de educación cognoscibles, investigables y que se puedan implementar en la arquitectura curricular.

Para comprobar la efectividad de la propuesta pedagógica se han sometido a análisis dos grupos: uno de control, en el que se aplicaba la enseñanza tradicional; y otro experimental, en el cual se introducía un taller pedagógico de carácter horizontal, para trabajar con la alfabetización visual del alumnado. Con este procedimiento se ha pretendido que la imagen quede grabada en la memoria gracias a la culturalización visual de la que el ser humano dispone en su bagaje cognitivo-cultural (Planella y Jiménez, 2019). Y dicho propósito se ha ejecutado a través de una metodología activa y participativa, la cual consigue involucrar al discente en el proceso de aprendizaje, al mismo tiempo que se promueve su atención y su motivación (López, 2015; Vuopala et al., 2020).

Este artículo se fragmentará en cuatro secciones. En primer lugar, se explicará el tipo de investigación, los participantes, así como los instrumentos y los materiales empleados; a continuación, se ofrecerá el desarrollo de la experiencia pedagógica, esto es, cómo los alumnos fueron deduciendo el funcionamiento de la figura retórica de la que se nutría la imagen publicitaria en cada caso. Posteriormente, se ofrecerá el análisis cuantitativo de la muestra. Por último, se extraerán las conclusiones pertinentes y las perspectivas de futuro. 


\section{Método}

Esta investigación se lleva a cabo en un centro de idiomas privado en el que acuden de lunes a jueves dos grupos para aprender español con un nivel B2. Según el Marco común europeo de referencia para las lenguas (VV.AA., 2002) en este nivel el discente entiende textos complejos de temas tanto concretos como abstractos; así como produce textos claros y detallados de temas generales y defiende su punto de vista; asimismo, se relaciona con hablantes nativos con bastante fluidez y naturalidad. En este nivel ya son capaces de entender el lenguaje literario y es el momento idóneo para introducir en el aula el mundo de la retórica tanto visual como lingüística.

En el artículo se comparan los resultados de la aplicación de dos metodologías diferentes a los grupos que componen la muestra del estudio. Uno de los grupos será el grupo de control. En este grupo se enseñará de forma tradicional las ocho figuras retóricas seleccionadas para esta investigación. El otro grupo será el grupo experimental. En él se aplicará una metodología basada en la cultura visual en la que se extraen conclusiones debido a la observación de imágenes publicitarias donde se explotan las ocho figuras que se trabajarán en el grupo control.

Durante el proceso de aprendizaje, los estudiantes elaboraron hipótesis sobre el funcionamiento de los recursos estilísticos utilizados para persuadir al comprador en ocho imágenes publicitarias. En otras palabras, el alumnado siguió un proceso intuitivo de los mecanismos visuales que aparecen en dichas imágenes. De este modo, tal y como se evidenciará en la investigación, el aprendizaje de aspectos retóricos tanto visuales como lingüísticos se hizo más atractivo para el estudiante, ya que, siguiendo a Fortune (1992), se reflexionó sobre el funcionamiento expresivo guiado por el docente sin la necesidad de tener que memorizar previamente el procedimiento estilístico de manera teórica. Así, se fomenta el aprendizaje significativo de la lengua, se facilita su 
memorización (Ausubel, 1986) y se presentan los contenidos como un juego de descubrimiento (González, 2014). Se trata de un enfoque experimental en el que se fomenta la motivación del alumnado y su autonomía en el aprendizaje, esto es, este modo funcional de orientar el aprendizaje permite que el discente sea el protagonista de su propio aprendizaje (Aliaga, 2021).

Para el diseño de la investigación se ha seguido un modelo cuasi-experimental, puesto que los grupos ya estaban formados y no se pudieron seleccionar los sujetos aleatoriamente. En estos casos, Campbell y Stanley (1966) recomiendan la utilización de dicho modelo y lo sitúan próximo al modelo experimental. Sin embargo, se debe considerar que se trata de grupos intactos, en los que la manera en que se formaron es independiente del experimento (Hernández et al., 2010). Como herramienta pedagógica se eligió un taller horizontal, puesto que es el que mejor se adapta a las características de la investigación, ya que el taller horizontal favorece el aprendizaje activo y "rompe con la rutina de la cotidianeidad de aulas, para ofrecer espacios para la reflexión y el análisis, y una forma diferente de acercarse al conocimiento" (Alfaro y Badilla, 2015, p. 137).

El objetivo principal que se buscaba a través de esta experiencia pedagógica era comprobar la efectividad del modelo propuesto para la enseñanza de figuras retóricas a partir del fomento de la cultura visual. De este modo, tal y como señalan Denzin y Lincoln (2012), la recogida de datos en ambos grupos, el control y el experimental, permitió cuantificar y comparar los resultados para comprobar su viabilidad.

Siguiendo a House (1991), la investigación asume que la realidad está estratificada, por eso los acontecimientos (susceptibles de ser analizados) son complementados por estructuras subyacentes, que pueden explicarse de manera eventual por estructuras pertenecientes a niveles mucho más profundos; de ahí que el proceso de descubrimiento sea continuo (House, 1991, p. 4). 
Como se ha comentado anteriormente, la muestra se organiza en dos grupos, uno de control y otro experimental. Se trata de dos grupos homogéneos en cuanto al nivel lingüístico (B2) como al número (25 por aula); sin embargo, es heterogéneo tanto en nacionalidad (inglesa, ucraniana, italiana, brasileña y filipina) como en edad (entre 25 y 55 años), lo que no interfiere en el buen funcionamiento del grupo clase. En la Tabla 1 se puede ver la distribución de la muestra.

Tabla 1. Distribución de la muestra

\begin{tabular}{lccc}
\hline & Hombres & Mujeres & Total \\
\hline Grupo de control & 8 & 17 & 25 \\
\hline Grupo experimental & 10 & 15 & 25 \\
\hline & 18 & 32 & 50 \\
\hline
\end{tabular}

Fuente: elaboración propia.

Así, la muestra se compone de 50 sujetos y queda distribuida de la siguiente manera: ocho hombres y diecisiete mujeres en el grupo de control, frente a diez hombres y quince mujeres en el grupo experimental.

El instrumento que se utilizó para la recogida de datos fue un cuestionario cerrado compuesto por 50 preguntas en las que había un fragmento de las rimas de Gustavo Adolfo Bécquer que contenía algunas de las ocho figuras retóricas que, con posterioridad, se trabajarían en el aula, ya fuese en formato tradicional o a partir de la cultura visual del alumnado. Dicho cuestionario fue validado por un grupo de ocho expertos en el ámbito, que confirmaron qué preguntas del cuestionario eran adecuadas y cuáles se hacía necesario modificar. Esto hizo posible analizar si los ítems diseñados eran sólidos para el tema objeto de estudio y si representaban a cada uno de los componentes planteados. 
La elección del número de preguntas responde a la pretensión de que hubiese el mismo número de fragmentos de cada figura trabajada (5 de cada tipo). En ellas se ofrecían 4 alternativas, para que el discente eligiese la correcta. La Figura 1 muestra un fragmento del cuestionario.

\section{CUESTIONARIO SOBRE FIGURAS RETÓRICAS}

Elige la opción correcta:

1) "Como el pájaro duerme en las ramas" (Rima VII)
a. Comparación
b. Sinécdoque
c. Antítesis
d. Metonimia

2) "Tu pupila azul, y cuando ríes," (Rima XIII)
a. Hipérbole
b. Metáfora
c. Sinécdoque
d. Antítesis

3) "Que anuncia en la noche del alma una aurora" (Rima I)
a. Personificación
b. Antítesis
c. Metonimia
d. Sinécdoque

4) "Por una mirada, un mundo" (Rima XXIII)
a. Antítesis
b. Elipsis
c. Personificación
d. Comparación 
Para la recogida de datos se procede de la siguiente manera: antes de la intervención se lleva a cabo un pre-test para medir el conocimiento de las figuras retóricas que poseen los discentes antes de la experiencia pedagógica; posteriormente se realizan las dos sesiones destinadas a la enseñanzaaprendizaje de las figuras retóricas, ya sea por el método tradicional (grupo de control) o por el método propuesto en esta investigación (grupo experimental). Y, por último, se efectúa el post-test, para poder comprobar la evolución de los discentes después de las sesiones formativas; cabe señalar que, a pesar de no aportar una certidumbre causal definitiva, un post-test sí representa los elementos esenciales a partir de los cuales se configuran todos los diseños cuasi-experimentales complejos, considerándose, por consiguiente, válido conforme a Fontes et al. (2001), para crear aproximaciones iniciales con las que sostener y fundamentar hipótesis emergentes, como la que aquí presentamos, basada en el análisis bibliográfico previo.

Para todo ello, se tendrán en cuenta dos variables: la variable dependiente (el número de aciertos) y la variable independiente, correspondiente a la aplicación de la metodología fundamentada en la cultura visual. Por lo tanto, en el post-test, dicha variable solo se tendrá en cuenta en el grupo experimental, puesto que es el que ha experimentado la propuesta innovadora.

La experiencia se puso en práctica un mes antes de que la Covid-19 hiciese que el país se paralizase, concretamente, se puso en práctica en febrero de 2020.

\section{Experiencia pedagógica}

En este epígrafe se comentará cómo se desarrolló la experiencia pedagógica en la que se introdujeron diversas figuras retóricas utilizadas en la publicidad visual a través de la alfabetización visual de los discentes, concretamente, 
se trabajó con cuatro figuras de pensamiento, tres de significación y una de dicción. Para ello, se utilizaron cuatro sesiones diferentes: unos días antes de comenzar con la experiencia pedagógica se llevó al aula el cuestionario sobre las figuras retóricas (Figura 1) y se explicó a los discentes que la semana siguiente se iba a realizar una actividad relacionada con esa temática; en la segunda y tercera sesión se trabajó la cultura visual propiamente; por último, una semana más tarde, se volvió a pasar el cuestionario de la sesión inicial. Es conveniente señalar que tanto en el grupo de control como en el experimental la temporalización se dispuso de la misma manera, no obstante, en este último grupo las imágenes publicitarias se quedaron expuestas en la clase, en un lugar visible por los alumnos durante esas tres sesiones intermedias.

En la primera sesión se explicó que la siguiente semana se iba a trabajar con contenido literario y se pasó el cuestionario al comenzar la evaluación inicial del proyecto. El resto de la clase se dedicó a otros aspectos.

En la segunda sesión, desarrollada el lunes, se siguió el mismo procedimiento a la hora de trabajar las ocho imágenes publicitarias que contienen figuras retóricas. En primer lugar, se proyectó la imagen del anuncio publicitario, se dejaron unos minutos de reflexión y se procedió con una lluvia de ideas para que los alumnos pudiesen deducir qué mecanismo retórico se había utilizado. A partir de aquí, se abría un debate en el que los discentes intercambiaban sus impresiones. Finalmente, se pegaba la imagen impresa en la pared con el nombre correspondiente a la figura retórica utilizada en el anuncio, con el propósito de fomentar la memoria visual de cada estudiante en el resto de sesiones previas a la sesión final de la experiencia pedagógica.

La primera figura retórica que se trabajó en el aula de español para extranjeros fue la hipérbole a través de un anuncio de la marca Chupa Chups (Figura 2), en esta imagen se muestra un caramelo enorme encima de una mujer. En la 
imagen se utiliza la hipérbole como reclamo publicitario. Según el Diccionario de términos literarios, la hipérbole "consiste en una exageración que aumenta o disminuye desmesuradamente las características de algo o de alguien" (Platas, 2004, p. 374). En la hipérbole visual, concretamente, se aumentará o disminuirá algún aspecto de la imagen en función de la idiosincrasia del producto ofertado, ya sea aumentando la capacidad del objeto en sí o disminuyendo los factores que destruyen el producto, es decir, "siempre está en relación 'desproporcionada' con los demás elementos" (Andueza, 2016, p. 73). Es más, dicha amplificación o disminución sobrepasa la credibilidad (Franquesa y Fontanills, 2013, p. 56).

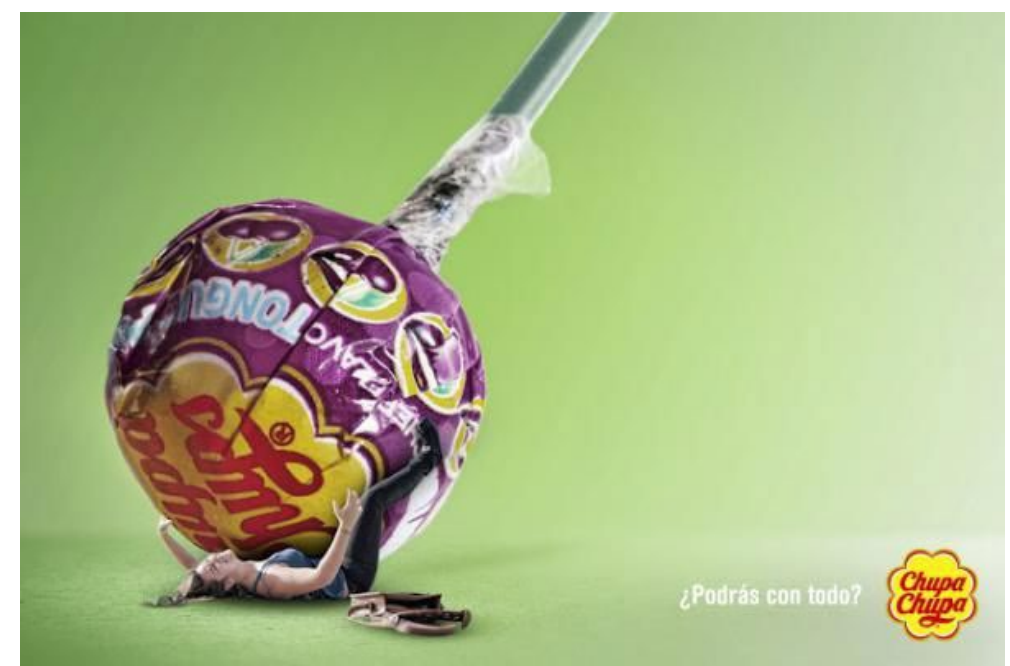

Figura 2. Hipérbole. 
Una vez que reflexionaron un poco sobre la imagen, lo primero que se indicó fue el tamaño del caramelo. Asimismo, otro aspecto que debatieron fue la postura de la mujer, pues se dedujo que mostraba alegría debido a la nueva cantidad que ofertaba la marca. Finalmente, a partir de la imagen, los discentes dedujeron que en este anuncio publicitario se buscaba esa visión desproporcionada del caramelo. Una vez que se definió el funcionamiento de la figura retórica, se pegó en la pizarra junto a su nombre. Es conveniente señalar que la definición no la ofrece la profesora, sino que son los propios alumnos los que la desarrollan con sus propias palabras y deducciones. La profesora solo interviene si falta algún aspecto importante que se debe considerar o si aparece algún aspecto erróneo.

A continuación, se proyectó el cartel publicitario con el que Renfe promocionaba el AVE en sus inicios. En él (Figura 3) se puede visionar una doble imagen: por un lado, la locomotora del tren; y, por otro, la cabeza de un águila calva, también conocida como águila americana, ambas con colores y formas similares. Se trata de una comparación entre ambas entidades. La comparación o símil es una figura retórica de pensamiento, en la que "se establece una relación de semejanza entre un término real (TR) y un término imaginario $(\mathrm{TI})$-enaltecedor o degradante- con el que el primero es comparado" (Platas, 2004, p. 152). En el ámbito visual, esta comparación se plasma a partir de imágenes. En este ejemplo, se aprecia la comparación de dos realidades distintas equilibradas, ya que lo que se pretende es simular, a través de la forma y los rasgos del águila, que el tren posee las mismas características, se tiende a priorizar las características que interesan y eludir el resto. 


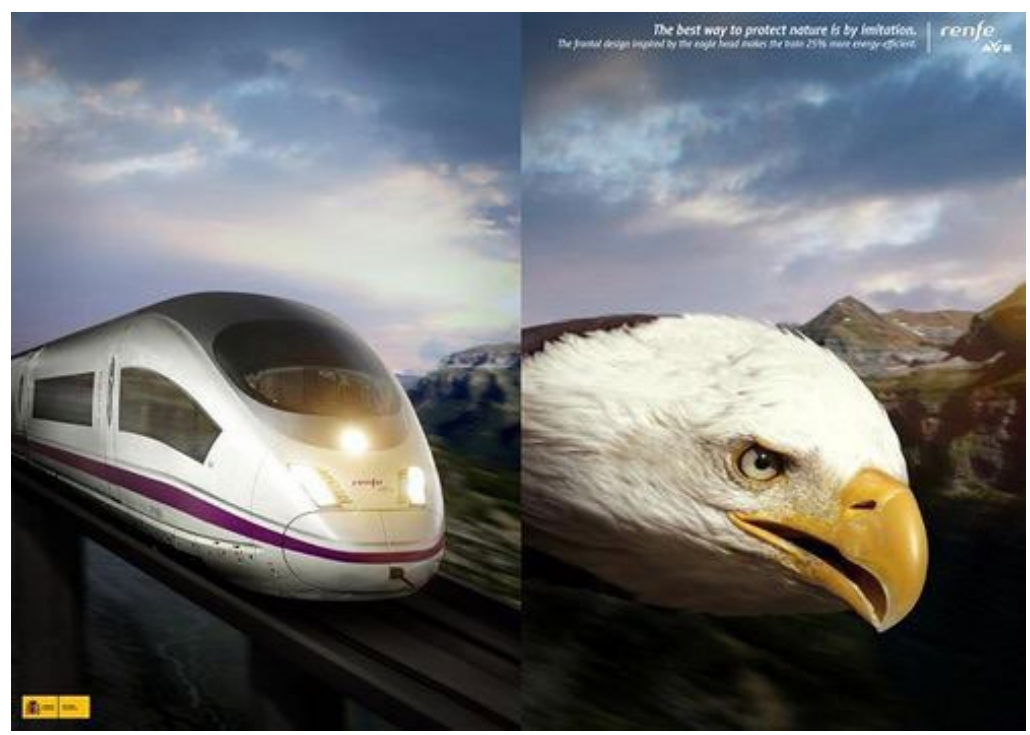

Figura 3. Comparación ave pájaro. Fuente: https://www.pinterest.es/pin/464152305320643499/

En este caso, los estudiantes dedujeron que se estaban comparando dos realidades. Esta imagen fue la más rápida que se dedujo y en la que estuvieron de acuerdo más fácilmente, puesto que en el día a día se suele utilizar bastante esta figura retórica tanto en el ámbito oral como en el visual (Franquesa y Fontanills, 2013). Al igual que en el caso anterior, una vez realiza la definición de la figura retórica se colgó en la pared junto a su nombre.

La tercera figura que se trató fue la antítesis a través de un anuncio de una joyería. En este caso, se aprecia el cambio de percepción de la mujer una vez que ha recibido el anillo de compromiso (Figura 4). La antítesis "consiste en la contraposición de palabras (antonimia) u oraciones que no encierran entre 
sí contradicción, por lo que no son generadoras de incoherencia" (Platas, 2004, p. 49). En lo que respecta a la antítesis visual, se contraponen dos imágenes opuestas.

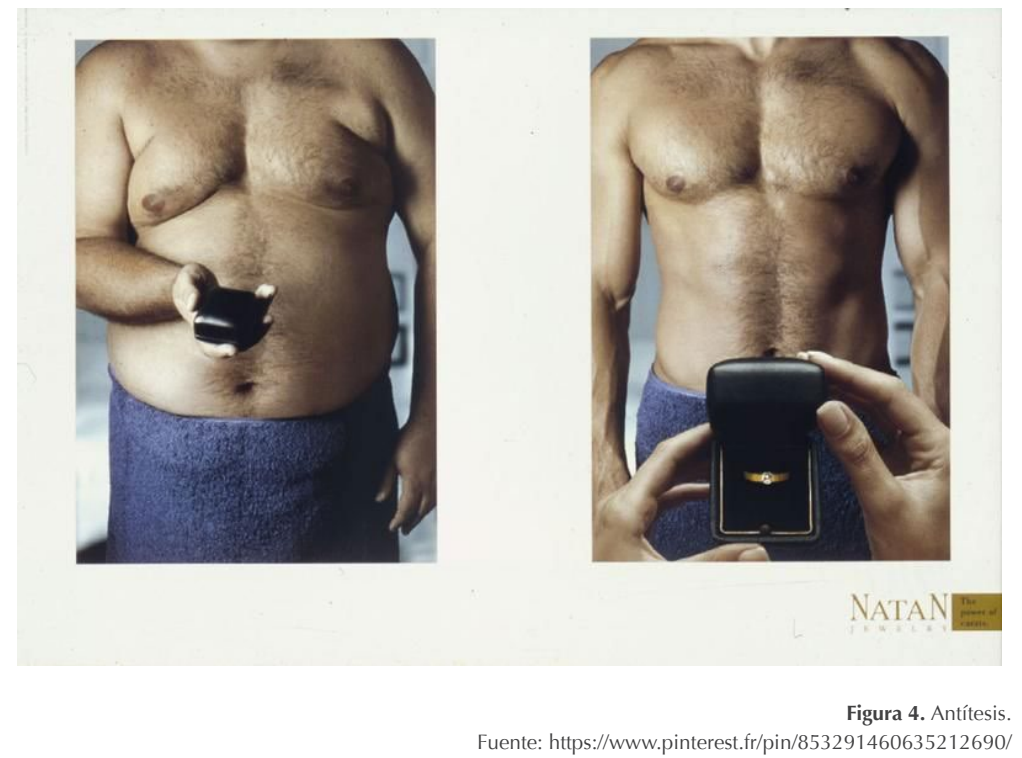

En el ejemplo planteado, los alumnos iban ofreciendo binomios de palabras contrapuestos como: antes-después, gordo-delgado, obeso-en forma, etc. A partir de aquí, se señaló que se trataba de palabras opuestas; este anuncio estaba creado a partir de la oposición, esto es, de la antítesis. Al igual que en los casos anteriores, una vez que se dedujo la figura retórica y se elaboró su definición, se puso la imagen en la pared junto a las otras con su nombre correspondiente. 
En la siguiente imagen que se presentó (Figura 5), había un león con una melena rubia, lisa y marcada. Se trata de un anuncio de cosmética en el que se intenta otorgar rasgos humanos al animal. La personificación o prosopopeya es una figura de pensamiento que "consiste en atribuir cualidades humanas a seres u objetos que no pueden tenerlas" (Platas, 2004, p. 677). En la imagen visual lo que se pretende es que el receptor identifique al animal que se representa en la imagen con él mismo. En este caso, se intenta transmitir la idea de que hasta la melena de un león puede peinarse con el producto anunciado.

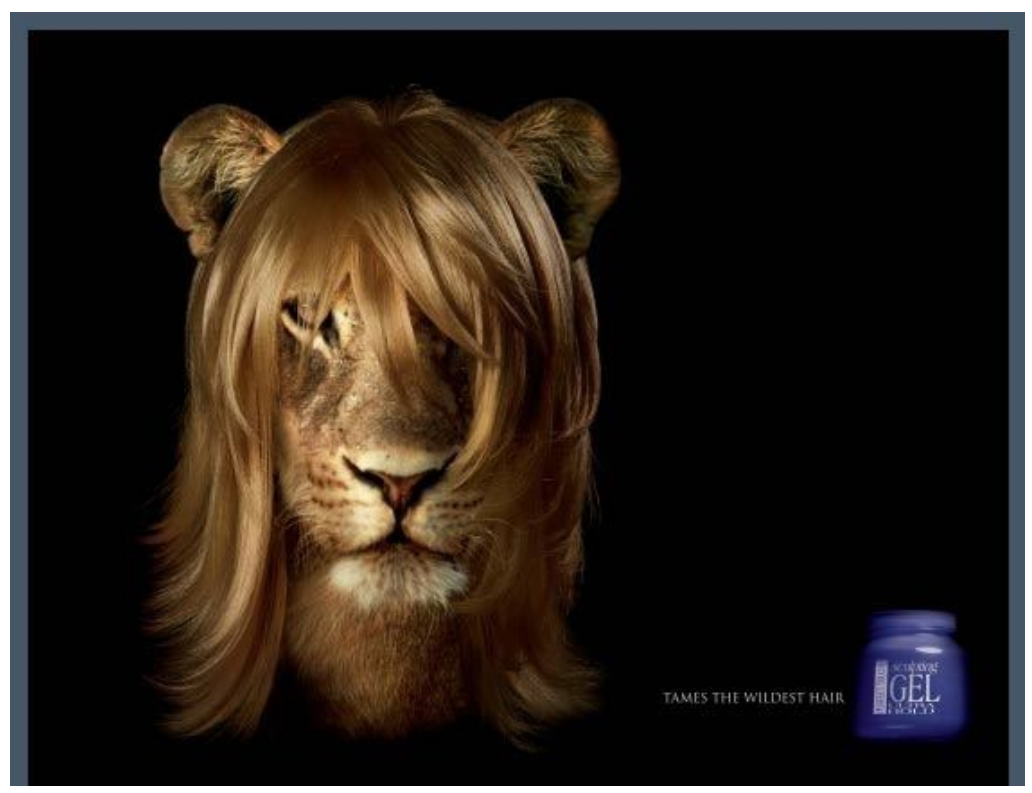

Figura 5. Personificación. Fuente: https://www.pinterest.es/pin/539446861590567888/ 
En este caso, en la lluvia de ideas que se desarrolla tras la visualización de cada imagen, los alumnos comentaron que el león parecía un humano y salieron nombres de personajes famosos. A través de estas respuestas, se guio a los discentes para que saliese la palabra persona y, a partir de ahí, el nombre de la figura retórica, esto es, personificación. El análisis de esta imagen fue divertido a través de las comparativas que hacían los alumnos del león con personajes públicos conocidos.

La siguiente lluvia de ideas se efectuó por medio de la metáfora (Figura 6), en la que se quiere mostrar que esta salsa de tomate está hecha solamente de tomate. La metáfora "consiste en trasladar el sentido propio de un término (término real, TR) a otro con el que se relaciona por semejanza (término imaginario, $\mathrm{TI}$ )" (Platas, 2004, p. 472). La metáfora visual:

(...) establece una comparación entre dos conceptos visuales, transmitiendo el significado de una imagen a otra, normalmente mediante la comparación. A diferencia de la sinécdoque visual las imágenes que se comparan en las metáforas visuales no tienen por qué tener una relación estrecha entre sí aunque sí guarden una semejanza, un parecido. (Andueza, 2016, p. 73)

En este caso, se ha creado el bote de kétchup Heinz como representación de uno de los componentes que lleva este producto. 


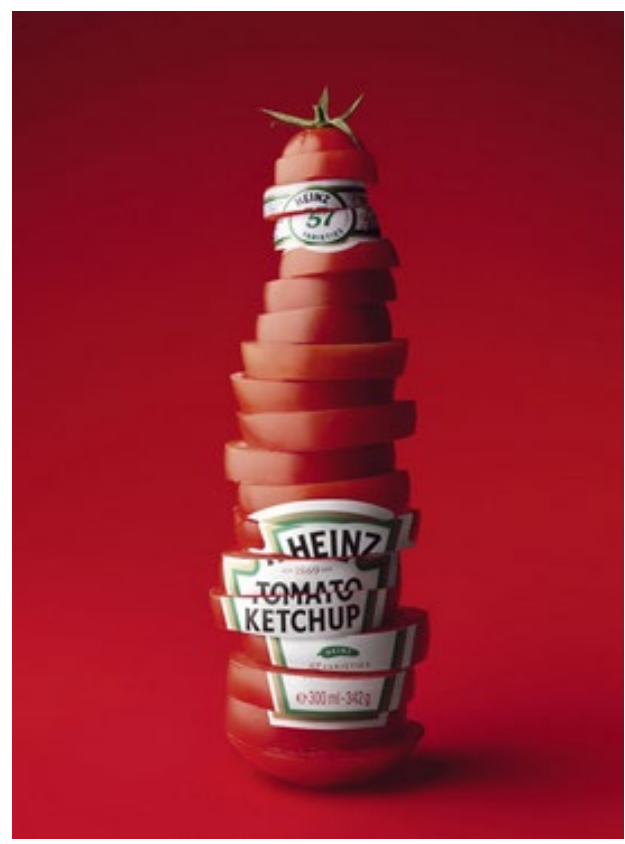

Figura 6. Metáfora.

Fuente: https://escueladigital.com.mx/blog/retorica-en-la-publicidad/

En este caso, los estudiantes presentaron más problemas a la hora de decidir el procedimiento de creación de este reclamo publicitario. Todos tenían claro que se quería simular el bote de tomate con un tomate real; sin embargo, no lograban interpretar que se trataba de un término real y otro imaginario. Con lo que se decidió mostrar conjuntamente las tres figuras de significación, puesto que se pensó que ayudaría a los discentes en el proceso deductivo.

A continuación, se presentó tanto la metonimia como la sinécdoque para poder ver las diferencias que entablan con la metáfora. Para ello, se utilizó 
el anuncio de chicle Orbit (Figura 7), y el de unas vitaminas que ayudan a fortalecer el pelo (Figura 8).

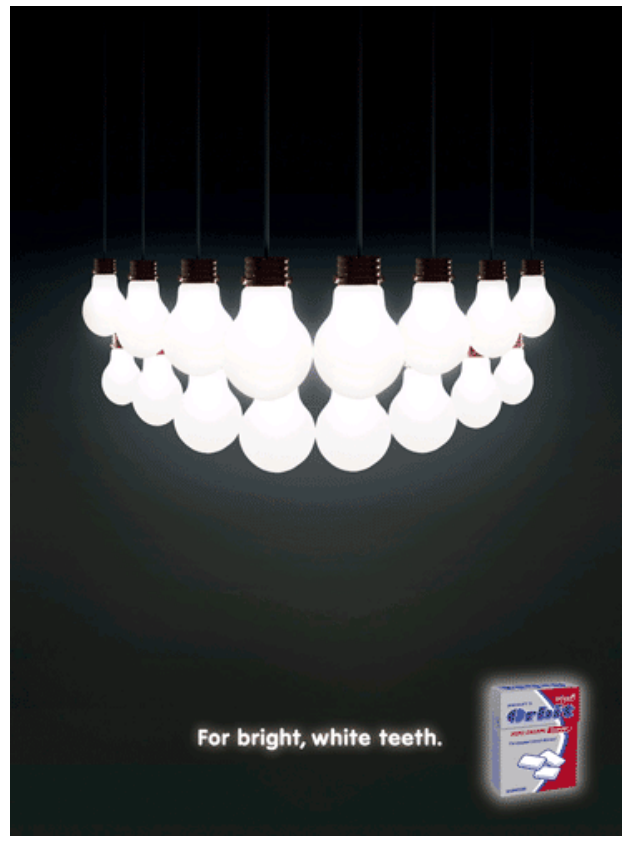

Figura 7. Metonimia. Fuente: https://www.pinterest.es/pin/319755642275111797/

La metonimia "consiste en la sustitución de un término por otro que mantiene con el primero una relación de contigüidad semántica" (Platas, 2004, p. 481). En esta metonimia visual se han sustituido los dientes por unas bombillas encendidas, puesto que lo que se quiere transmitir es que al comer este chicle se consigue que la dentadura brille a causa de su blancura. 


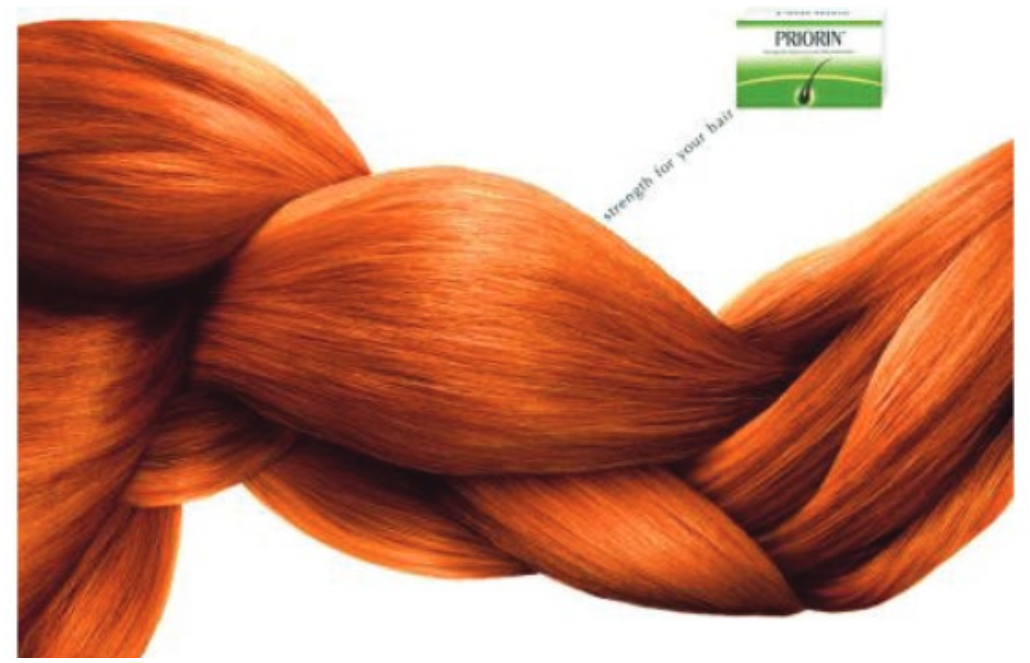

Figura 8. Sinécdoque. Fuente: https://es.slideshare.net/FrankartDiseoWeb

La sinécdoque consiste en una relación de continuidad "que se debe a la restricción o ampliación del significado de un concepto único. (...) En la sinécdoque puede expresarse el todo por la parte o la parte por el todo" (Platas, 2004, p. 774). La sinécdoque visual "consiste en utilizar una parte de algo para referirse a un todo, o viceversa" (Andueza, 2016, p. 73). En este caso, se ha pretendido resaltar la fuerza del cabello.

Una vez presentadas las tres imágenes, se utilizó una lluvia de ideas conjunta, en la que se iban proponiendo palabras para las tres imágenes. El tratamiento de las tres figuras de forma conjunta se debe a la proximidad que hay entre ellas para que los alumnos comprobasen de forma visual en qué se diferencian. Así, a través de la imagen se consiguió que apreciasen la diferencia entre un procedimiento retórico y otro. Aunque es conveniente señalar que fueron las 
tres figuras retóricas más difíciles de tratar. En este caso, la profesora tuvo que intervenir en más ocasiones dirigiendo las preguntas hacia el objetivo buscado.

La última figura que se trabajó en esta sesión fue la elipsis (Figura 9), por medio de un anuncio publicitario de la marca McDonald's en el que se ha suprimido la imagen. La elipsis es una figura de dicción que consiste en la "omisión de una o más palabras que pueden deducirse fácilmente, aunque no estén, ni siquiera próximas, en el texto" (Platas, 2004, p. 243). La elipsis visual "se establece cuando una imagen aparente o expresamente está incompleta. Se produce una omisión 'visual' de algo que tiene que ver con la escena" (Andueza, 2016, p. 74). Esta ausencia posee tanta fuerza que proporciona significado a la representación, ya que invita al receptor a reconstruir mentalmente la imagen (Franquesa y Fontanills, 2013).

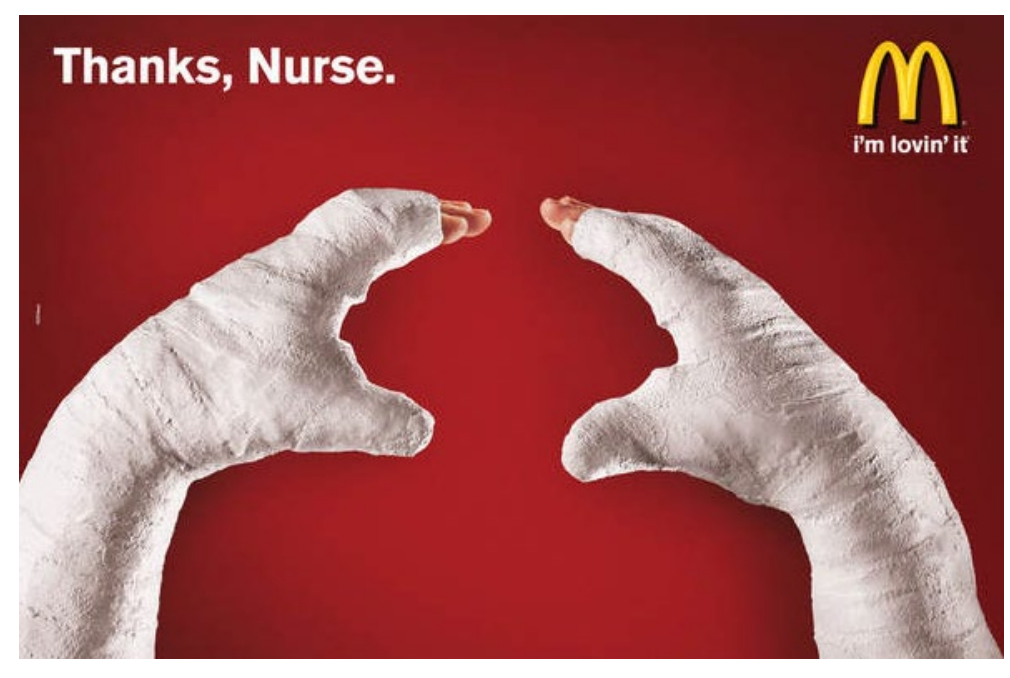

Figura 9. Elipsis. Fuente: https://www.pinterest.es/pin/399835273174145794/ 
Esta última figura retórica fue también rápida de deducir, puesto que casi todas las palabras que aparecían en la lluvia de ideas estaban relacionadas con la elipsis: borrar, ocultar, desaparecer, etc. No obstante, la mirada también se dirigió hacia el hecho de que las manos estuviesen vendadas.

Una vez que se introdujeron las ocho figuras retóricas, se comentó al alumnado que se dejarían las imágenes en la pared durante unos días. De este modo, se terminó la sesión.

En la siguiente sesión, se abrió un debate sobre las imágenes que se habían tratado en la sesión anterior. Se utilizaron cuestiones guía como, por ejemplo, ¿qué imagen os ha parecido más original? o ¿en cuál de ellas era más fácil deducir la figura retórica que aparecía? En las siguientes dos sesiones se trabajaron otros aspectos gramaticales.

En la última sesión, se quitaron las imágenes publicitarias de la pared y se llevó al aula el cuestionario inicial para que se volviese a completar.

El desarrollo de la experiencia didáctica sirvió, como apuntan Bergman y Coxon (2005), para abordar el objetivo de la investigación y para captar el sentido compartido de lo que resulta relevante en el entorno de los significados de los contenidos curriculares tratados en la experiencia educativa, que fueron pedagógicamente diseñados. El rigor de lo investigado, por lo tanto, se va a considerar de acuerdo a la evolución del proceso indagatorio, considerando las particularidades propias asentadas en el contexto de los dos grupos que conforman la muestra del estudio y teniendo presente las aportaciones de todos los participantes en el mismo, siguiendo el principio de exhaustividad, que conlleva la atención al vínculo entre el objeto de estudio y el desarrollo íntegro de sus efectos (Whittemore et al., 2001). 


\section{Resultados y discusión}

En este apartado se llevará a cabo un análisis cuantitativo de los datos obtenidos a través de los instrumentos de evaluación, esto es, se analizarán los datos del pre-test y del post-test tanto en el grupo de control como en el experimental para comprobar si realmente la propuesta pedagógica basada en la cultura visual es o no efectiva.

En primer lugar, se contemplará la evaluación inicial que se emprendió antes de comenzar con la práctica docente. Teniendo en cuenta la globalidad de las respuestas, el grupo de control obtuvo más errores que el grupo experimental (Figura 10).

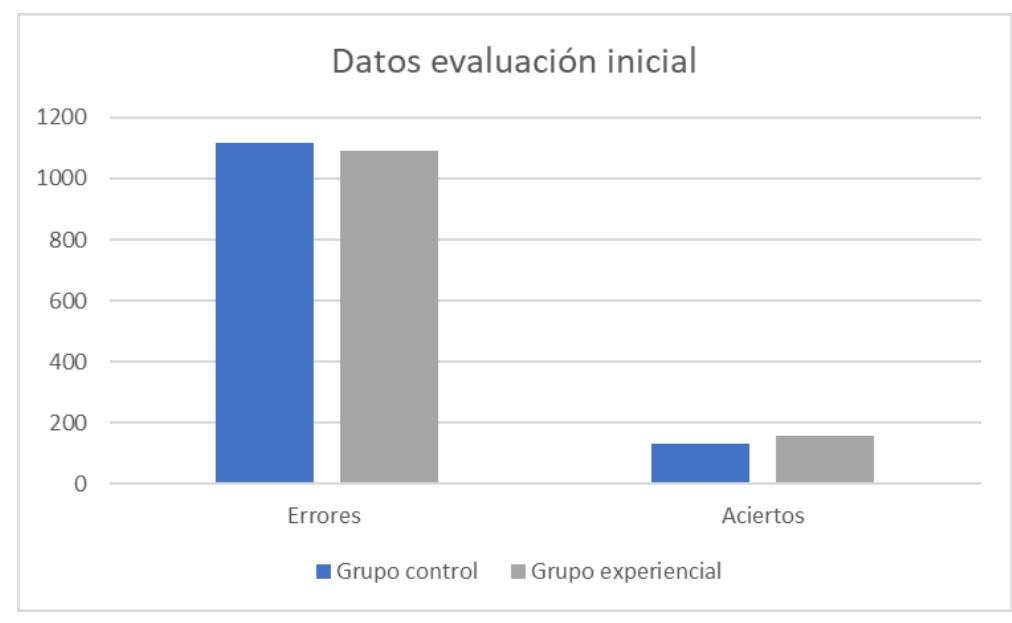

Figura 10. Datos obtenidos en el pre-test Fuente: elaboración propia. 
Como se muestra en la gráfica, pese a que el grupo experimental tuvo más aciertos que el grupo de control, la diferencia entre ambos es mínima, puesto que el grupo experimental obtuvo un $12,72 \%$ frente al $10,72 \%$ del grupo control. No se trata de una diferencia significativa.

A continuación, se mostrará una gráfica (Figura 11) con los datos obtenidos en el post-test:

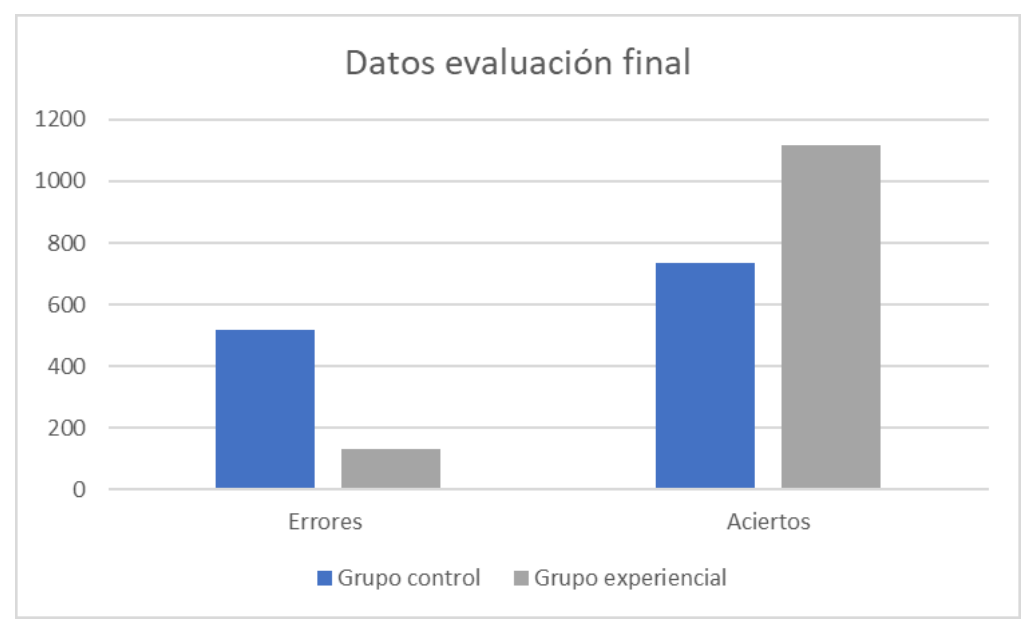

Figura 11. Datos obtenidos en el post-test. Fuente: elaboración propia.

Al comparar los resultados obtenidos en la evaluación final tanto del grupo control como del grupo experimental, se aprecian unos resultados concluyentes en los que, a pesar de que en ambos grupos hay una mejora, la más significativa se halla en el grupo experimental, en el que aparece un $89,36 \%$ de aciertos, frente al 58,64\% correspondiente al grupo control. 
Atendiendo a un análisis individual de cada grupo, las tablas 2 y 3 muestran la evolución de ambos grupos:

Tabla 2. Resumen grupo control

\begin{tabular}{|c|c|c|c|}
\hline \multicolumn{4}{|c|}{ GRUPO CONTROL } \\
\hline \multirow{2}{*}{$\begin{array}{c}\text { Evaluación inicial } \\
\text { Total aciertos }\end{array}$} & \multirow{2}{*}{$\begin{array}{c}\text { Evaluación final } \\
\text { Total aciertos }\end{array}$} & \multicolumn{2}{|c|}{ Mejora / empeora } \\
\hline & & Diferencia & Porcentaje (\%) \\
\hline 10 & 35 & 25 & 71,43 \\
\hline 9 & 30 & 21 & 70 \\
\hline 10 & 20 & 10 & 50 \\
\hline 8 & 30 & 22 & 73,33 \\
\hline 3 & 35 & 32 & 91,43 \\
\hline 2 & 28 & 26 & 92,86 \\
\hline 1 & 27 & 26 & 96,3 \\
\hline 3 & 22 & 19 & 86,36 \\
\hline 5 & 20 & 15 & 75 \\
\hline 10 & 19 & 9 & 47,37 \\
\hline 3 & 21 & 18 & 85,71 \\
\hline 6 & 18 & 12 & 66,67 \\
\hline 3 & 35 & 32 & 91,43 \\
\hline 4 & 36 & 32 & 88,89 \\
\hline 2 & 37 & 35 & 94,59 \\
\hline 5 & 33 & 28 & 84,85 \\
\hline 6 & 30 & 24 & 80 \\
\hline 7 & 36 & 29 & 80,56 \\
\hline 9 & 33 & 24 & 72,73 \\
\hline 8 & 32 & 24 & 75 \\
\hline 3 & 29 & 26 & 89,66 \\
\hline 4 & 29 & 25 & 86,21 \\
\hline 5 & 32 & 27 & 84,38 \\
\hline 6 & 29 & 23 & 79,31 \\
\hline 2 & 37 & 35 & 94,60 \\
\hline
\end{tabular}

Fuente: elaboración propia. 
Tabla 3. Resumen grupo experimental

\begin{tabular}{|c|c|c|c|}
\hline \multicolumn{4}{|c|}{ GRUPO EXPERIENCIAL } \\
\hline \multirow{2}{*}{$\begin{array}{c}\text { Evaluación inicial } \\
\text { Total aciertos }\end{array}$} & \multirow{2}{*}{$\begin{array}{c}\text { Evaluación final } \\
\text { Total aciertos }\end{array}$} & \multicolumn{2}{|c|}{ Mejora / empeora } \\
\hline & & Diferencia & Porcentaje (\%) \\
\hline 7 & 40 & 33 & 82,5 \\
\hline 6 & 45 & 39 & 86,67 \\
\hline 5 & 41 & 36 & 87,80 \\
\hline 8 & 43 & 35 & 81,40 \\
\hline 9 & 42 & 33 & 78,57 \\
\hline 2 & 44 & 42 & 95,45 \\
\hline 3 & 45 & 42 & 93,33 \\
\hline 4 & 46 & 42 & 91,30 \\
\hline 9 & 44 & 35 & 79,55 \\
\hline 6 & 47 & 41 & 87,23 \\
\hline 5 & 45 & 40 & 88,89 \\
\hline 4 & 48 & 44 & 91,67 \\
\hline 3 & 42 & 39 & 92,86 \\
\hline 6 & 41 & 35 & 85,37 \\
\hline 9 & 42 & 33 & 78,57 \\
\hline 7 & 45 & 38 & 84,44 \\
\hline 8 & 46 & 38 & 82,61 \\
\hline 10 & 47 & 37 & 78,72 \\
\hline 6 & 46 & 40 & 86,96 \\
\hline 5 & 47 & 42 & 89,36 \\
\hline 7 & 48 & 41 & 85,47 \\
\hline 8 & 47 & 39 & 82,98 \\
\hline 9 & 46 & 37 & 80,43 \\
\hline 7 & 45 & 38 & 84,44 \\
\hline 6 & 45 & 39 & 86,67 \\
\hline
\end{tabular}

Fuente: elaboración propia. 
Como se puede comprobar a través tanto de las gráficas globales como de las tablas individuales, ambos grupos mejoran después de las sesiones dedicadas a la enseñanza-aprendizaje de las figuras retóricas. Sin embargo, por medio de la propuesta basada en la cultura visual y en su alfabetización, el grupo experimental no solo mejora, sino que, en conjunto, lo hace de forma más equitativa. Atendiendo a los porcentajes más bajos de mejora, aparece una diferencia significativa de un 30\% aproximadamente entre el grupo de control, que presenta un $47,37 \%$, frente al grupo experimental con un $78,57 \%$. En la parte más alta de la clasificación esta diferencia es menor, ya que no llega al $1 \%$. No obstante, llama la atención que el caso mayor de mejora se produce en el grupo de control con un $96,3 \%$, frente al 95,45\% del grupo experimental. Si bien es cierto que esta mejora se genera en más ocasiones en el grupo experimental, en el que el incremento es equitativo entre todos los componentes del grupo. En cuanto a la diferencia numérica media entre la evaluación inicial y la final de ambos grupos, se aprecia un aumento de 38,32 aciertos en el grupo experiencial frente a un 23,96 en el grupo de control, lo que corresponde al $85,72 \%$ y al $80,35 \%$, respectivamente.

De esta manera, a tenor de los resultados, se puede decir que los significados de los objetivos curriculares se encuentran recorridos por la indicidad que la reflexividad de la cultura visual introduce en la acción educativa; no obstante, es el uso concreto en el contexto determinado de interacción el que canaliza, en última instancia, el significado de aquello que se está impartiendo.

Cabe mencionar que los porcentajes de mejora, en general, son bastante elevados. Esto se debe tanto a que la evaluación inicial se efectuó sin que los discentes tuviesen un conocimiento previo de las figuras retóricas en la segunda lengua como, también, al hecho de que la construcción y el logro de la subjetividad se canalizaran en una serie de resultados objetivos. Por eso, "la cultura es el vínculo objetivo y compartido, que unifica los universos 
particulares de significados y acciones, de prácticas, de razonamientos y de interacciones" (Redon y Angulo, 2017, p. 31).

Estos resultados, en los que la media de aciertos en la evaluación final del grupo experiencial oscila en torno al $86 \%$, permiten constatar que la cultura visual transforma información en conocimiento y, en consecuencia, conocimiento en educación. El desarrollo de la práctica educativa desarrollada con los instrumentos de la investigación hizo posible crear un ámbito pedagógico cognoscible y realizable; en concreto, el uso de la publicidad como eje curricular hizo posible integrar tecnología y práctica en los objetivos didácticos de la clase de español para extranjeros. El resultado de la investigación implicó el desarrollo de conocimientos y destrezas que ayudaron en la manera de implementar capacidades específicas propias del curso (determinadas en los objetivos curriculares de esta).

A raíz de todo ello, se puede aseverar que el uso de la cultura visual permite explicar e interpretar figuras retóricas como la hipérbole, la comparación, la antítesis, la personificación, la metáfora, la metonimia, la sinécdoque y la elipsis. Entre ellas, las figuras de pensamiento y de dicción fueron las que más porcentaje de acierto obtuvieron, Ilegando la comparación, la personificación y la antítesis a rozar el 100\%, esto es, 97,87\%, 96,45\% y 95,64\%, respectivamente. Sin embargo, la sinécdoque, la metáfora y la metonimia fueron las de menor porcentaje de acierto, siendo un 76,45\%, 74,17\% y $74 \%$, respectivamente. Así, entre otras cosas, se refuerza el potencial de la cultura visual como constructo curricular al servicio de la acción educativa de una clase de lengua. 


\section{Conclusiones}

A través de estas líneas se ha mostrado una experiencia pedagógica en la que se fomenta la cultura visual para llevar al aula de español para extranjeros ocho figuras retóricas, a partir de la hipótesis de que la alfabetización visual facilita la comprensión y el aprendizaje en el aula. Para ello, se ha llevado a cabo una investigación cuasi-experimental, con una metodología activa y participativa basada en la observación y en la deducción de procedimientos retóricos utilizados en publicidad. La efectividad de la propuesta pedagógica se ha comprobado por medio de un análisis contrastivo entre dos grupos de español, correspondientes a un nivel B2, a los que se le aplicaba metodologías diferentes: uno de control, en el que se aplicaba la enseñanza tradicional; y otro experimental, en el que se introducía un taller pedagógico de carácter horizontal. Con ello, se ha podido comprobar que la cultura visual permite introducir de forma efectiva contenido pedagógico en el aula.

La sociedad actual está inmersa en un mundo visual que puede y debe explotarse en las aulas. La imagen permite desarrollar distintos referentes en el contexto educativo, puesto que "la cultura visual, como escenario de agencias y significación, presenta una oportunidad para atender los cambios generacionales que permitan transformar las estrategias pedagógicas para la enseñanza" (Ligarretto, 2020, p. 142).

La propuesta pedagógica que se explica en este trabajo partía de una premisa según la cual el mundo social es, él mismo, un producto social, sujeto a la posibilidad de ser transformado; es, en consecuencia, intrínsecamente dinámico, y, cuando lo circunscribimos a una investigación basada en una experiencia pedagógica, un proceso situado, pero evolucionable. $\mathrm{Y}$ es precisamente sobre este margen de evolución sobre el que se basó el estudio, 
un proceso de investigación que ha dado cuenta del contexto, las condiciones, las relaciones y los recursos empleados.

Tras la práctica pedagógica se contrastó que, a pesar de que la metodología tradicional había obtenido mejoras, la propuesta innovadora por medio de la cultura visual era más efectiva pues se obtuvo una media de acierto del $85,72 \%$ frente al $80,35 \%$ de la primera. Asimismo, cabe señalar que en el grupo experimental el porcentaje de acierto es más homogéneo que en el de control, puesto que el rango de este es el doble que en el grupo experimental.

Se trata de una experiencia piloto, ya que ayudó a comprobar las limitaciones de la propia investigación, disfunciones didácticas como, por ejemplo, que se hubiese hecho necesario visionar primero las figuras de pensamiento y dicción, y, por último, las de significación. Además, estas últimas deberían analizarse de manera conjunta para ayudar a los discentes en su deducción. En este sentido, y apuntando una línea de investigación futura, puede resultar interesante llevar esta propuesta a otros grupos (el desarrollo de la pandemia no permitió seguir aplicándola), así como también extrapolarla a investigaciones con muestras de alumnos de la Educación Secundaria Obligatoria. De esta manera, focalizar los estudios en otras etapas educativas permitirá analizar la interconexión entre cultura visual, procesos y estructura etaria en la comprensión del fenómeno (para ver si, en función de la etapa educativa, la implementación de la cultura visual adquiere mayor o menor relevancia y significatividad).

Asimismo, estudios como este deben servir para que se asuma la necesidad de crear todo tipo de unidades didácticas, en la enseñanza de la lengua, donde se fomente el uso de la alfabetización visual como metodología docente. Efectivamente, tal y como se ha evidenciado, la cultura visual arropa sentidos, completa significados $y$, si se configura con una cierta planificación y se le 
otorga entidad pedagógica, articula procesos habilitados para canalizar, de manera eficaz, los contenidos curriculares.

\section{Referencias}

Acaso, M. (2009). El lenguaje visual. Paidós.

Alfaro, A. y Badilla, M. (2015). El taller pedagógico, una herramienta didáctica para abordar temas alusivos a la Educación Ciudadana. Revista Electrónica Perspectivas, 10, 81-146.

Aliaga-Aguza, L. M. (2021). Escenario educativo y clima de aula de la clase de español para extranjeros. En Docencia, ciencia y humanidades: hacia una enseñanza integral en la universidad del siglo XXI. Dykinson S.L.

Aliaga, L. M. (2020). Hacia una didáctica de la lengua y la literatura comunicativa, Opción: Revista de Ciencias Humanas y Sociales, 92, 628-650.

Andueza, M. (2016). Didáctica de las artes plásticas y visuales en educación infantil. Universidad Internacional de La Rioja, La Rioja.

Arriaga, A., Marcellán, I. y Jiménez de Aberasturi, E. (2018). Presentación. Mediación crítica en arte y cultura visual. Pulso: revista de educación, 41, 13-17.

Ausubel, D. P. (1986). Educational Psychology. A cognitive View. Trillas.

Bang, E. C., Cano, L., Casado, I., Martínez, M. O. C., Crespo, C., Dávila, B., Garrido, J. C., Gozalo, L., Hernández, A. M., Herrero, C., Medina, I. y Toboso, C. (2021). Etwinning y la transformación digital educativa. eCO. Revista Digital de Educación y Formación del Profesorado, 18, 1-47.

Barthes, R. (1990). La aventura semiológica. Paidós.

Bergman, M. M. y Coxon, A. P. (2005). La calidad en métodos cualitativos. Forum: Qualitative Social Research, 6(2).

Campbell, D., \& Stanley, J. (1966). Experimental and quasi-experimental designs for research. Rand McNally.

Cao, M. L. F. (1998). La retórica visual como análisis posible en la didáctica del arte y de la imagen. Arte, Individuo y Sociedad, 10, 39-62. 
Carratalá, F. (2013). Tratado de didáctica de ortografía española. Octaedro.

Denzin, N. K. y Lincoln, Y. S. (2012). El campo de la investigación cualitativa. Gedisa.

Dondis, A. D. (1992). La sintaxis de la imagen. Introducción al alfabeto visual. Gustavo Gili.

Fontes, S., García, C., Garriga, A. J., Pérez-Llantada, M. C. y Sarriá, E. (2001). Diseños de investigación en psicología. UNED.

Fortune, A. (1992). Self-study grammar practice: learner's views and preferences. ELT Journal, 46(2), 160-171.

Franquesa, A. F. y Fontanills, D. G. (2013). Imagen y comunicación visual. Universitat Oberta de Catalunya, CC-BY-SA, 70.

González, A. B. (2014). Estrategias de aprendizaje. Una propuesta didáctica de inducción gramatical. Revista TodoEle. http://www.todoele.net/actividades/Actividad_maint. asp? ActividadesPage $=5$ \&Actividad_id $=343$

Hernández, R., Fernández, C. y Baptista, M. P. (2010). Metodología de la investigación. McGrawHill.

House, E. R. (1991). Realims in Research. Educational Researcher, 20(8), 2-25.

Ligarretto, R. E. (2020). Meme educativo: experiencia para una pedagogía de la cultura visual. Revista Educación y Ciudad, 39, 131-145. https://doi.org/10.36737/01230425. n39.2020.2341

López, F. (2015). Reflexiones sobre la gramática en el aula de ELE. En Actas del Programa de formación para profesorado de español como lengua extranjera (pp. 171-182). Manchester.

Moles, A. (1975). La comunicación y los mass media. Mensajero.

Piscitelli, A. (2005). Internet, la imprenta del siglo XXI. Gedisa.

Planella, J. y Jiménez, J. (2019). Gramáticas de un mundo sensible de corpógrafos y corpografías. Utopía y praxis latinoamericana: revista internacional de filosofía iberoamericana y teoría social, 16(87), 16-26.

Platas, A. M. (2004). Diccionario de términos literarios. Espasa Calpe.

Redon, S. y Angulo, J. F. (2017). Investigación cualitativa en educación. Miño Dávila. 
Toro, M. (2019). Las TIC como mediación didáctica en el desarrollo de la multiexpresividad en la educación inicial; el caso de la Institución Educativa Alfonso López Pumarejo (San José de Guaviare) (tesis doctoral).

Villafañe, J. (2006). Introducción a la teoría de la imagen. Pirámide.

Vuopala, E., Guzmán, D., Aljabaly, M., Hietavirta, D., Malacara, L., \& Pan, C. (2020). Implementing a maker culture in elementary school - students' perspectives. Technology, Pedagogy and Education, 29(5), 649-664.

VV.AA. (2002). Marco común europeo de referencia para las lenguas: aprendizaje, enseñanza y evaluación. Anaya.

Whittemore, R., Chase, S. K., \& Lynn, C. (2001). Validity in qualitative research. Qualitative Health Research, 11(4), 522-537.

Cómo citar: Aliaga, L. M. (2022). La cultura visual y la publicidad como herramientas para enseñar las figuras retóricas en el aula de español para extranjeros. Revista KEPES, 19(25), 565-597. https://doi.org/10.17151/kepes.2022.19.25.19 